\title{
RESEARCH
}

Open Access

\section{Spatial segregation of the biological soil crust microbiome around its foundational cyanobacterium, Microcoleus vaginatus, and the formation of a nitrogen-fixing cyanosphere}

\author{
Estelle Couradeau ${ }^{1,2,3+}$ (D) Ana Giraldo-Silva ${ }^{1,4 \dagger}$, Francesca De Martini ${ }^{1}$ and Ferran Garcia-Pichel ${ }^{1,4^{*}}$
}

\begin{abstract}
Background: The bundle-forming, filamentous, non-nitrogen-fixing cyanobacterium Microcoleus vaginatus is a pioneer primary producer, often the dominant member of the biocrust microbiome, and the main source of leaked organic carbon. We hypothesized that, by analogy

to the rhizosphere of plant roots, M. vaginatus may shape the microbial populations of heterotrophs around it, forming a specialized cyanosphere.

Results: We found that a small, selected subset of OTUs was significantly enriched in close proximity to M. vaginatus. Furthermore, we also found that a majority of bacteria (corresponding to some two thirds of the reads) were significantly more abundant away from this cyanobacterium. Phylogenetic placements suggest that all typical members of the cyanosphere were copiotrophs and that many were diazotrophs (Additional file 1: Tables S2 and S3). Nitrogen fixation genes were in fact orders of magnitude more abundant in this cyanosphere than in the bulk biocrust soil as assessed by qPCR. By contrary, competition for light, $\mathrm{CO}_{2}$, and low organic carbon concentrations defined at least a part of the OTUs segregating from the cyanobacterium.

Conclusions: We showed that M. vaginatus acts as a significant spatial organizer of the biocrust microbiome. On the one hand, it possesses a compositionally differentiated cyanosphere that concentrates the nitrogen-fixing function. We propose that a mutualism based on $\mathrm{C}$ for $\mathrm{N}$ exchange between $\mathrm{M}$. vaginatus and copiotrophic diazotrophs helps sustains this cyanosphere and that this consortium constitutes the true pioneer community enabling the colonization of nitrogen-poor soils. On the other hand, a large number of biocrust community members segregate away from the vicinity of $\mathrm{M}$. vaginatus, potentially through competition for light or $\mathrm{CO}_{2}$, or because of a preference for oligotrophy.
\end{abstract}

Keywords: Biocrust, Cyanosphere, Microcoleus vaginatus, Diazotrophs

\footnotetext{
* Correspondence: ferran@asu.edu

${ }^{\dagger}$ Estelle Couradeau and Ana Giraldo-Silva contributed equally to this work

${ }^{1}$ School of Life Sciences, Arizona State University, 427 E. Tyler Mall, Tempe, AZ 85287, USA

${ }^{4}$ Center for Fundamental and Applied Microbiomics, Biodesign Institute,

Arizona State University, 1001 S. McAllister Ave., Tempe, AZ 85282, USA

Full list of author information is available at the end of the article
}

(c) The Author(s). 2019 Open Access This article is distributed under the terms of the Creative Commons Attribution 4.0 International License (http://creativecommons.org/licenses/by/4.0/), which permits unrestricted use, distribution, and reproduction in any medium, provided you give appropriate credit to the original author(s) and the source, provide a link to the Creative Commons license, and indicate if changes were made. The Creative Commons Public Domain Dedication waiver (http://creativecommons.org/publicdomain/zero/1.0/) applies to the data made available in this article, unless otherwise stated. 


\section{Background}

Biological soil crusts (biocrusts) are soil-surface microbial communities based on microbial or cryptogamic phototrophs that develop in areas where light can penetrate directly to the soil surface unimpeded by a layer of plant litter ([1] for a primer and [2,3] for monographs). They are prominent in arid lands, where they contribute several important ecosystem properties, including the protection of soils against erosion and nutrient fertilization of the areas they cover.

Most studies on the biology and ecology of biocrust organisms have centered on the primary producers (largely cyanobacteria, but also sometimes microalgae, lichens, and mosses), and much has been learned about their particular adaptations and ecology. And yet, biocrusts represent miniature ecosystems that are phylogenetically diverse, in which a variety of ecological functions are expressed. They constitute a particular type of soil microbiome, one in which the primary producers are an essential but certainly far from exclusive part [4, 5]. Pioneering filamentous, bundle-forming cyanobacteria, such as Microcoleus vaginatus and $M$. steenstrupii, initiate biocrust formation by stabilizing the surface of loose soils [6], allowing a succession that involves other cyanobacteria [7], bacteria [8], archaea [9], and fungi [10], as well as the lichens [11] and mosses [12] that are typical of the best developed crusts of milder environments. Most of the bacteria and archaea appear to be heterotrophs [9, 13], although crusts do contain significant populations of bacterial and archaeal chemolithotrophs that are crucial for nitrogen cycling $[14,15]$. Under unusually long periods of wetness, spore-forming bacteria [16] or even methanogenic archaea [17] may develop sizeable biocrust populations. Microbial diversity and population density increase as succession proceeds [18]. Even in successionally young biocrusts, biomass (estimated as total cell counts, or DNA content) is orders of magnitude larger than those typical of desert soils, and the microbial communities within them show evidence of vertical stratification similar to those of microbial mats or biofilms [1]. At a larger, landscape scale, varying soil properties influence the biocrust microbiome composition [19], as do climatic variations at a continental scale $[14,20]$.

Biocrust microbes remain desiccated, and hence inactive, most of the time but, upon wetting, become quickly hydrated and active [21]. During pulses of activity, high metabolic rates constrained within small spaces result in the rapid formation of steep chemical gradients and microenvironments, which include oxygen-supersaturated zones close to the surface and anoxic zones some 1-3 mm deep [22]. Biocrusts are not only locally, but also globally relevant. They cover some 12\% of the Earth's continental area [23] and are major players in the global $\mathrm{N}$ cycle, as some $\sim 31 \%$ of the biological nitrogen fixation on land can be attributed to their activity [24, 25]. Their global standing stocks have been estimated to reach in the order of $54 \times 10^{12} \mathrm{~g} \mathrm{C}$ [26]. The oldest fossil remains of biocrust communities date back to the Proterozoic [27], and it is thought that these systems were determinant for the global ecology of early continents before the advent of land plants [28].

In a large proportion of biocrusts worldwide, $M$. vaginatus plays a central role by being both a foundational species and a metabolic pivot to the biocrust community. Uniquely, $M$. vaginatus does not only fix carbon but also excrete a large fraction of its photosynthate directly into the soil $[29,30]$. In using a plant analogy, $M$. vaginatus would serve both as a leaf and a root. However, $M$. vaginatus does not have the capacity to fix nitrogen [31, 32], so it remains somewhat surprising that a non-diazotroph be the main colonizer of such typically $\mathrm{N}$-limited, bare arid soils. In mature crusts, most of the nitrogen fixation is attributed to heterocystous cyanobacteria [7] and, in early crusts that lack the latter, to the activity of heterotrophic diazotrophs [33].

We hypothesized that $M$. vaginatus may rely on the $\mathrm{N}_{2}$ fixation of other bacteria for their nitrogen needs and that such metabolic interaction may result in an enrichment of certain bacterial types in the proximity of its bundles within the biocrusts. By analogy to a plant rhizosphere [34], this sphere of influence would be the basis of a spatial "cyanosphere" (contraction of the words "cyanobacterium" and "sphere") based on functional interactivity. We tested this hypothesis directly taking advantage of the large size of $M$. vaginatus bundles, which makes it possible to physically excise and isolate them from the rest of the biocrust community, enabling the characterization and comparative analyses of the microbial communities found close and away from its bundles.

\section{Results}

\section{A cyanosphere composed of a selected subset of the} biocrust microbiome exists around $M$. vaginatus

We carried out our analyses in samples from two contrasted geographical locations, one from the warm Chihuahuan Desert (Fort Bliss or FB) and one from the cold Great Basin Desert (Hill Sandy or HSN) (Fig. 1). The two sites and their soils and biocrusts are fully described elsewhere [35]. After excising and isolating single bundles of $M$. vaginatus from the soil, we analyzed the microbiome tightly associated with them using high-throughput $16 \mathrm{~S}$ rRNA gene amplicon sequencing and compared using bioinformatics the composition of the microbial community intimately associated with these bundles $(n=44)$ to the total biocrust community analyzed separately $(n=6)$ (Additional file 2: Table S1), as the simplest assessment of spatial organization: close to and away from $M$. vaginatus. In a first check, we made sure that our original microscopic assignment of the bundles to $M$. vaginatus was 

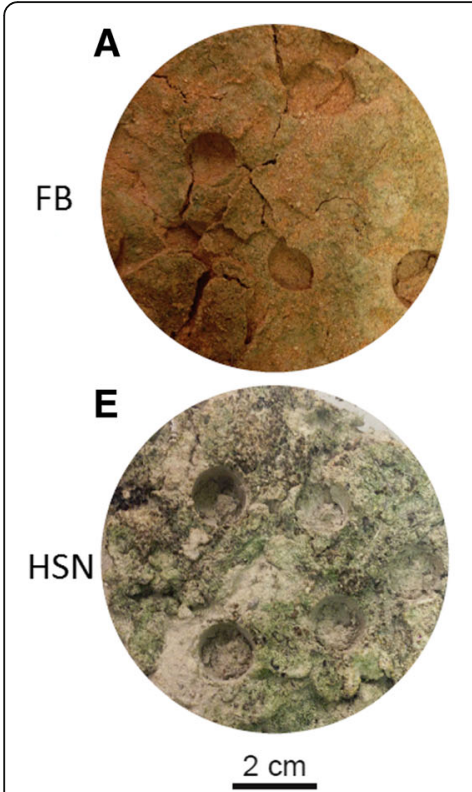
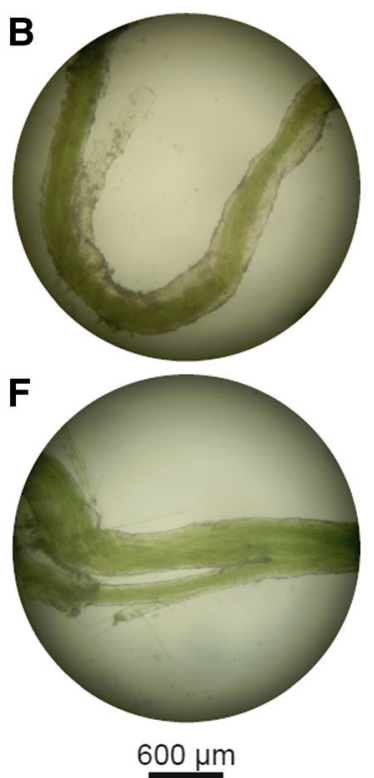
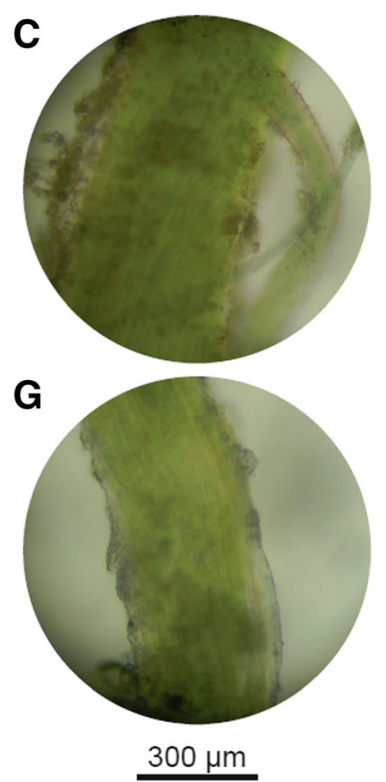

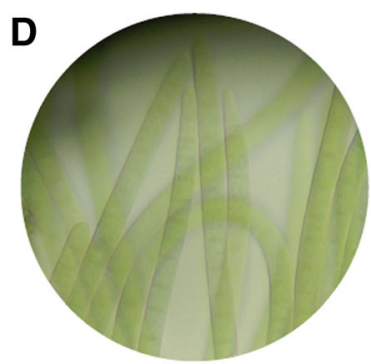

H

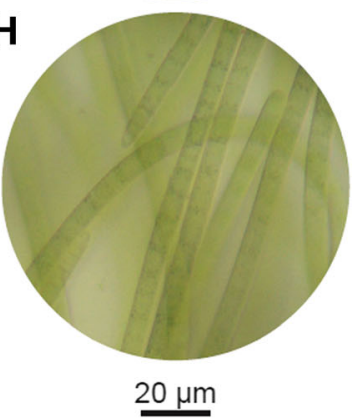

Fig. 1 Biocrust samples from the Chihuahuan and the Great Basin deserts. a, e Top views of Chihuahuan (a) and Great Basin (e) biocrusts before bundle picking. Depressions are from coring for the bulk soil samples. b, f Examples of cyanobacterium bundles picked from the biocrust. Each bundle comprised the cyanobacterium and the exopolysaccharide sheath that bundles the filaments together and hosts the cyanosphere community. c, $\mathbf{g}$ A closer look at the bundles. $\mathbf{d}$, $\mathbf{h}$ Single $M$. vaginatus thricomes under the compound microscope $(\times 100)$ for preliminary identification, before corroborating their identity by $16 \mathrm{~S}$ rRNA gene typing. FB, Fort Bliss—hot desert; HSN, Hill Sandy soil—cold desert

correct, as other bundle-forming cyanobacterial species populate biocrusts (Fig. 2). This was indeed the case. We then compared the composition of the rest of the microbiomes (to the exclusion of all OTU's attributable to $M$. vaginatus). We found that overall the bundle OTU richness (average chao1 $202 \pm 97$ ) was an order of magnitude lower than the richness of the total biocrust community (average chao1 $2107 \pm 320$ ). While the OTU richness of bundles was not different between locations, the HSN site biocrust community was significantly more diverse (average chao1 $2432 \pm 56$ ) than that of the FB site (average chao1 $1801 \pm 115$ ) (Additional file 2: Table S1).

A non-metric multidimensional scaling (NMDS) ordination of the beta diversity Bray-Curtis metric on the Hellinger-transformed OTU table (Fig. 3a) revealed that the composition of the bundle communities was distinct from those of their respective biocrust soil community of origin (Adonis, $F=4.7, p$ value $=0.001$ ), forming a compositional "cyanosphere" (by analogy to the plant rhizosphere). The cyanosphere composition was also differentiated according to the sampling location (Great Basin or Chihuahuan Desert).

In order to further probe the factors driving the differentiation between cyanosphere and biocrust microbiome, we calculated the ratio of abundance of each operational taxonomic unit (OTU) in the bundles vs. the bulk soil, for those OTUs that were detected in both settings (669 shared OTUs at FB, and 2177 shared OTUs at HSN). The frequency distribution of these ratios was clearly skewed towards negative values (Fig. 3b), implying that many more microbial types tended to segregate away from $M$. vaginatus than tended to aggregate within its cyanosphere. In order to identify the OTUs involved in this spatial organization, we used the DESeq2 method [36], which computes statistical significance for differential distributions of OTUs between two possible outcomes. Twenty OTUs in the cold desert cyanospheres (HSN) and two OTUs in those from the hot desert (FB) could be classified with statistical confidence $(p<0.05$; listed in Additional file 1: Tables S2 and S3, respectively), as consistent $M$. vaginatus close neighbors across different bundles, while 758 OTUs (HSN) and 592 OTUs (FB) were statistically more abundant away from it (Fig. 3c; listed in Additional file 3: Table S4). This analysis confirmed that the significant difference between the cyanosphere and the total soil community is driven by a small number of bacteria associated with $M$. vaginatus bundles (aggregating OTUs), while there are large numbers of bacteria (segregating OTUs) that were preferentially found away from them, as part of the bulk soil. Accounting for the relative contribution of each OTU, we could compute that altogether more than two thirds of all the biocrust bacteria were significantly affected in their spatial distribution by the presence of $M$. vaginatus (Table 1, Fig. 3c), the large majority segregating away from the cyanosphere.

From the 5 negative control samples (sterilized sewing cotton thread) that we analyzed in the same way in an effort to account for any external contamination (i.e., operator or 


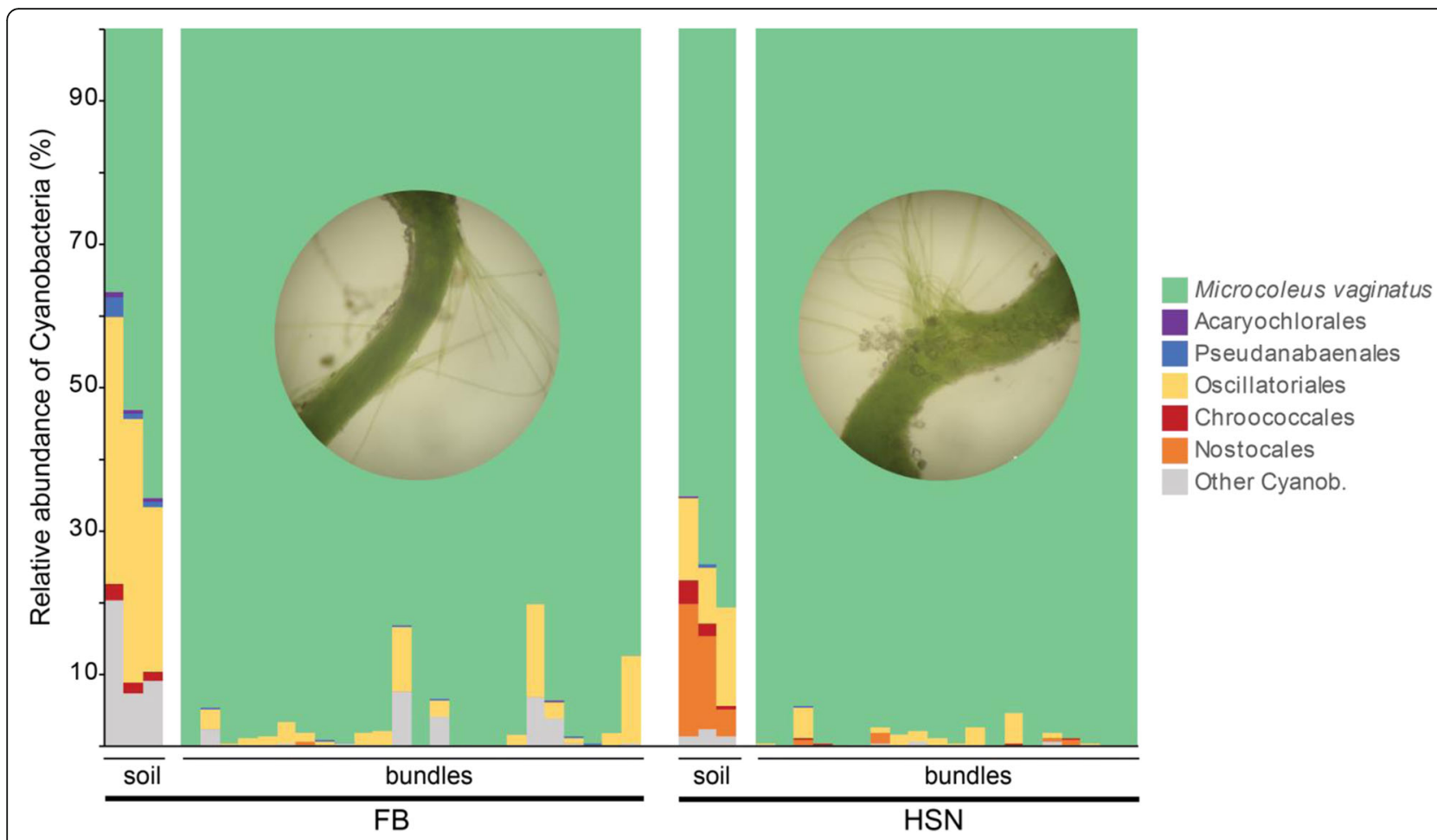

Fig. 2 Cyanobacterial community structure and bundle identification. Relative abundance of cyanobacteria based on high-throughput sequence of $16 \mathrm{~S}$ rRNA genes and bioinformatics analysis in M. vaginatus bundles and bulk biocrust soil from each location. Three OTUs belonging to $M$. vaginatus constituted the most abundant cyanobacterium in the community and the overwhelming majority of the cyanobacteria in the excised bundles. FB, Fort Bliss—-hot desert; HSN, Hill Sandy soil—cold desert

environmental source) during our handling of bundle samples, we recovered a total of 92 OTUs, among which 4 matched (>99\% sequence similarity) 1 of our aggregating OTUs (Additional file 4: Table S5). A conservative take of this result is that they are all contaminants. However, 1 out of these 4 OTUs has been detected by other methods as one of the most common heterotrophic nitrogen fixers in early biocrust stages [33]. The same OTU matches (100\%) a culture recently isolated from $M$. vaginatus bundles in nitrogen-free media (Nelson et al., unpublished data). This suggests that we may not have the taxonomic resolution to resolve the true status of these OTUs and therefore decided not to filter out these 4 OTUs, but rather to flag them in Additional file 4: Table S5.

\section{The $M$. vaginatus cyanosphere is enriched in nitrogen- fixing members}

We further analyzed the identity of the 21 OTUs that were statistically bona fide cyanosphere members using a refined phylogenetic placement in search for functional inference (the "Methods" section, Additional file 1: Tables S2 and S3, and Additional file 3: Table S4). We found that all taxonomically assignable OTUs could be inferred to be from copiotrophic bacteria, which are rather uncommon in organic-poor desert soils and otherwise typical of organic-rich rhizospheres, animal microbiomes, or dung (among them several enterobacteria, pseudomonads, Streptococcus, Bacteroides, and Myxobacteria; Additional file 1: Tables S2 and S3 and Additional file 2). We also found that at least 6 OTUs from those 21 could be inferred by phylogenetic placement to be likely members of $\mathrm{N}_{2}$-fixing clades (Additional file 1: Tables S2 and S3 and Additional file 2). Three of these OTUs (assigned to Escherichia/Shigella, Acinetobacter, and Stenotrophomonas) matched (> 99\%) 3 of the phylotypes identified elsewhere as important heterotrophic diazotrophs of biocrusts through ${ }^{15} \mathrm{~N}$-DNA SIP and genomic analyses [33]. This suggests that diazotrophic capacity may be a common denominator of the cyanosphere community. In order to gauge the relative potential for $\mathrm{N}_{2}$ fixation of the cyanosphere community more directly, we performed quantitative PCR to determine the ratio of nifH genes (coding for a nitrogenase subunit) to $16 \mathrm{~S}$ rRNA copy numbers existing in the bundle cyanosphere vs. that in the bulk biocrust microbiome. We found that the nifH gene was some 100-fold more abundant in the cyanosphere of $M$. vaginatus bundles (Fig. 4) than in the bulk soil crusts, regardless of geographic origin. 


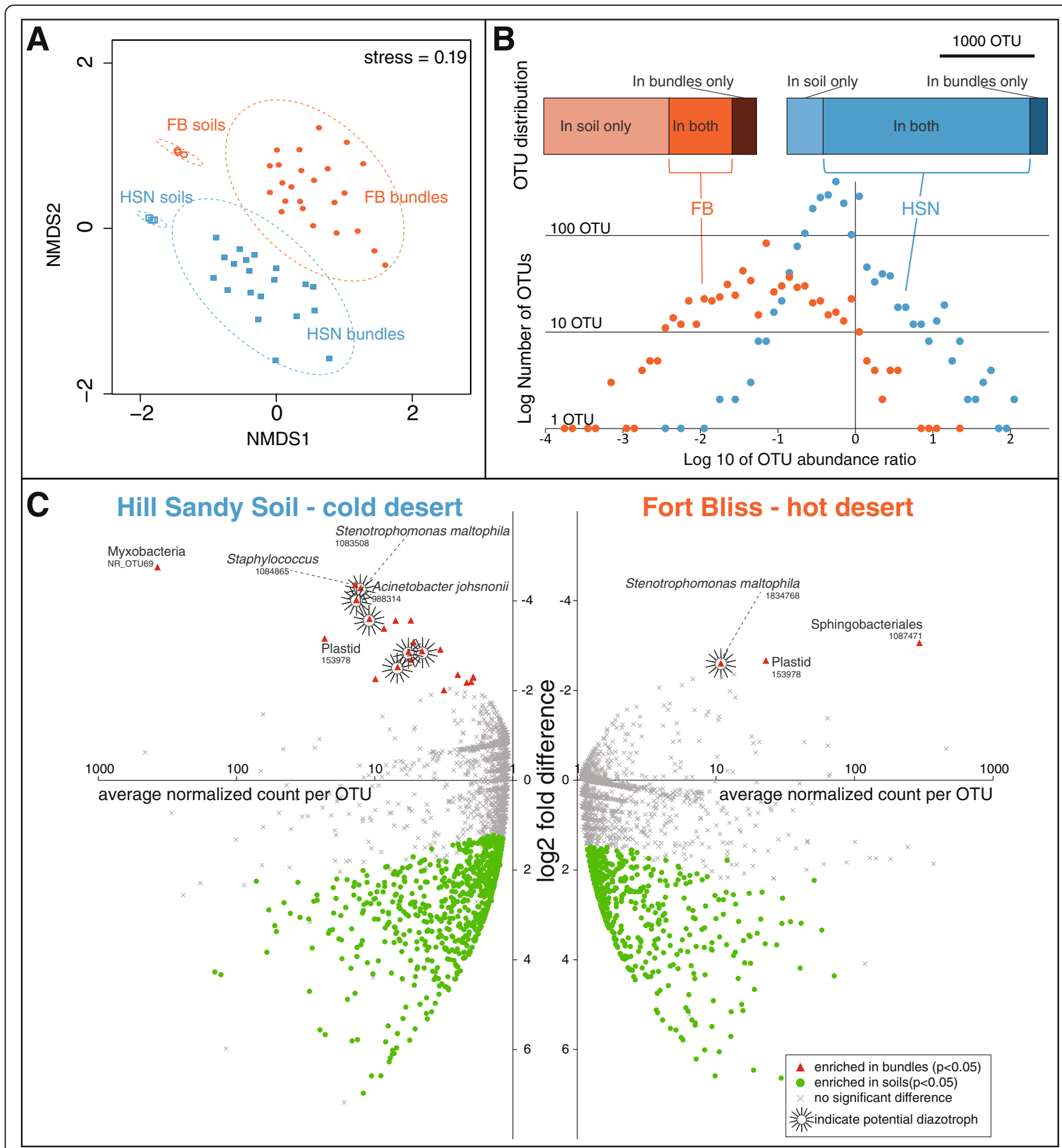

Fig. 3 Spatial separation of microbial types close to, and away from, M. vaginatus in soil crusts. a NMDS ordination of Bray-Curtis pairwise distance computed on the Hellinger-transformed OTU composition in bulk soil or M. vaginatus cyanospheres (sans M. vaginatus), with 95\% confidence ellipses drawn for each with a stress value of 0.19 . In each setting, bulk soil communities differ in composition from their respective M. vaginatus cyanosphere (bundle communities). FB, Chihuahuan Desert (hot desert); HSN, Great Basin Desert (cold desert). b Frequency distribution of the ratios in relative abundance for microbial OTUs that co-occurred in the cyanospheres of M. vaginatus and in the bulk soil crusts, showing a skewed distribution towards segregation. c Differential abundance of microbial OTUs (sans M. vaginatus) in the cyanosphere vs. bulk soil crust community assessed with the DESeq2 method for cold and hot desert locations. For each OTU, the average normalized counts are plotted against their differential abundance. OTUs that were differentially abundant $(p<0.05)$ are represented as solid triangles and circles, while cross symbols denote those with non-significant preference. Negative values indicate enrichment in the cyanosphere and positive in the bulk soil crust 
Table 1 Bacterial population size (as percentage of total $16 \mathrm{~S}$ rRNA gene reads) of bacteria that show spatial responsiveness to M. vaginatus. Aggregating and segregating OTUs were determined statistically as per Fig. 1c, each OTU was then weighed by its relative abundance, and all contributions added

\begin{tabular}{lcc}
\hline & FB soils & HSN soils \\
\hline Aggregating & 0.22 & 0.13 \\
Segregating & 52.55 & 69.97 \\
Non-significant & 47.23 & 29.89 \\
\hline
\end{tabular}

Oligotroph, phototroph, and autotroph members among those segregated from $M$. vaginatus

We again used phylogenetic placement on the 1350 soil OTUs that were significantly more abundant away from $M$. vaginatus bundles, in an attempt to refine their potential function. Since most microbial taxonomic diversity is not well described functionally, we could not find relevant inferences for the majority of these OTUs, which prevented us from carrying out a fully quantitative estimation. Instead, we asked specific hypotheses based on logical predictions. A simple such prediction would be that competition for light may drive other phototrophs away from the dominant $M$. vaginatus. Indeed, no other known phototrophs were found among aggregating bacteria and all bona fide phototrophs were among the segregating OTUs, including other cyanobacteria, proteobacterial purple non-sulfur phototrophs, and several Chloroflexi. In a similar manner, one could predict that competition for $\mathrm{CO}_{2}$ would tend to segregate other autotrophs from $M$. vaginatus, which was again the case (including all other photoautotrophs like cyanobacteria, purple non-sulfurs, some Chloroflexales, as well as nitrifying chemolithoautotrophic Archaea and Bacteria, such as Nitrososphaera and Nitrospira). A final case could be made on the basis of the fact that bacteria in the cyanosphere tend to gather uncommon copiotrophs (such as enterobacteria, pseudomonads, Streptococcus, Bacteroides, and Myxobacteria; Additional file 1: Tables S2 and S3), so it is possible that oligotrophs grow better away from the sources of leaking photosynthate that $M$. vaginatus represents. Our analysis revealed that members of well-known oligotrophic bacterial genera (Caulobacter, Asticcacaulis, Brevundimonas, and Sphingomonas in the Proteobacteria; Modestobacter, Blastococcus, Geodermatophilus, Nocardioides, and Arthrobacter in the Actinobacteria; Fimbriimonas, Chthonomonas, and Armatimonas in the Armatimonadetes; and Longimicrobium in the Gemmatimonadetes) were preferentially represented among the segregating microbiome fraction, but absent from the cyanosphere

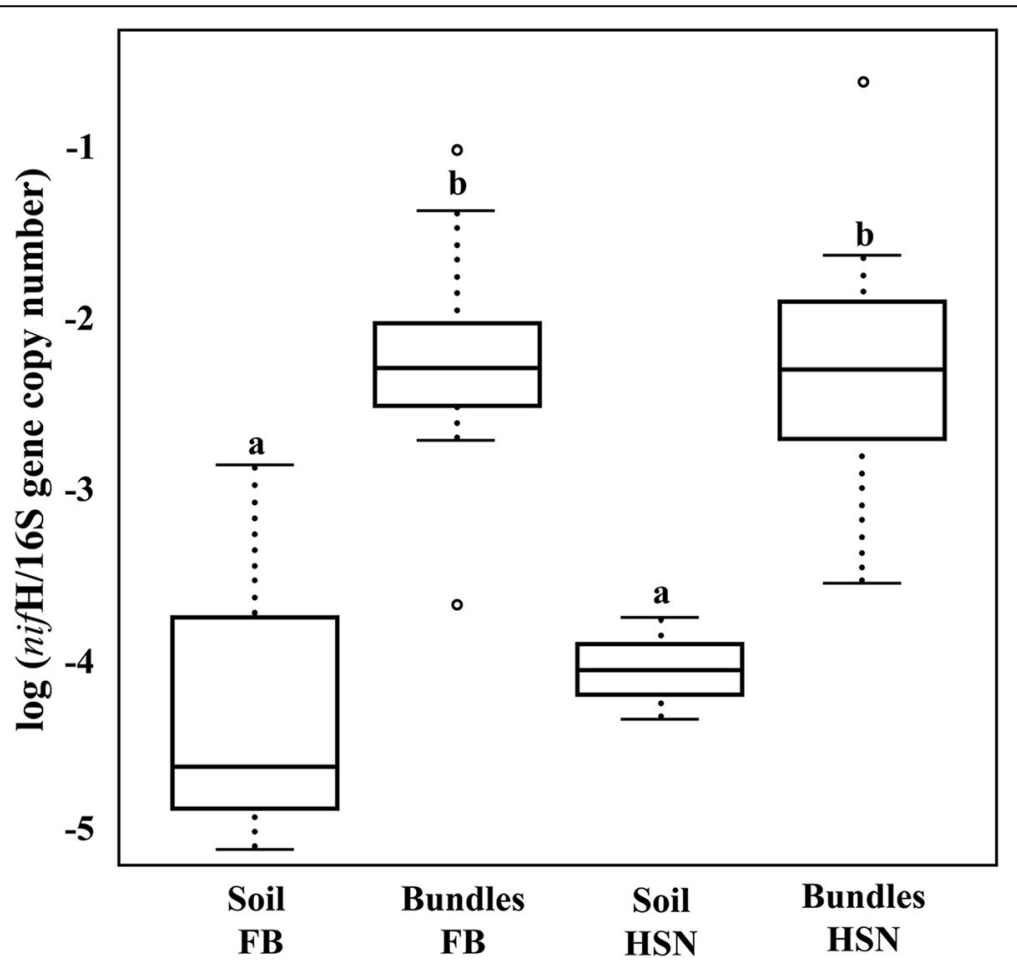

Fig. 4 Ratio of the nifH to $16 \mathrm{~S}$ rRNA gene copy number in bulk biocrust soil and M. vaginatus bundle (cyanosphere) communities. The nifH/16S rRNA ratio was obtained by quantitative PCR assays of each and was two to three orders of magnitude higher in the cyanosphere than in the bulk soil crust. A one-way ANOVA test showed that differences between groups (M. vaginatus bundles vs. bulk biocrust soil) were significant $(p$ value $<0.005)$ 
(Additional file 1: Tables S2 and S3 and Additional file 3: Table S4).

\section{Discussion \\ The cyanosphere as a differentiated compartment of the biocrust microbiome}

We could show that the community closely associated to $M$. vaginatus bundles, while containing many of the same microbial OTUs found in the bulk biocrust soil, differs from it in that it attracts a specific set of bacteria that are otherwise quite rare. This phenomenon is not unlike microbial hotspots that are found around plant roots in the soil [37], and so we called this specialized community the cyanosphere. This is consistent with the developing notion of an evolutionarily deeply rooted continuum of specific interconnections between phototrophic and heterotrophic systems, from "algal spheres" to root microbiomes [38]. Interestingly, all OTUs that define the $M$. vaginatus cyanospheres would belong to the "rare biosphere" [39] by virtue of their extremely low abundance in the biocrust microbiome (the median rank of aggregating OTUs in soils was 2549th), and yet they may be playing significant functional roles in biocrust systems.

The cyanosphere compartment possesses differential features that might explain why a specific set of bacteria thrive in it, compared to the rest of the biocrust soils. First, it is an organic carbon hotspot based on the high concentration of the extracellular polymeric substances (EPS) that make up a bundle's sheath $[40,41]$ and by the dynamic excretion of a large variety of small molecular weight organics by $M$. vaginatus cells [30]. The EPS sheath likely offers means for physical anchoring of bacteria and might help retain hydration water during desiccation [42]. Altogether, the cyanosphere likely constitutes top real estate within the biocrust where occupancy might be determined by microbe-microbe competition for this resource-rich hotspot [43].

\section{M. vaginatus' cyanosphere may be at least partly based on a mutualistic $\mathrm{C}$ for $\mathrm{N}$ exchange}

Clearly, the abundance of nitrogenase nif $\mathrm{H}$ gene in the cyanosphere is roughly 100-fold higher than that in the bulk crust soil, which strongly suggests that nitrogen fixation "concentrates" there, a fact supported by the high abundance of typical nitrogen-fixing taxa among cyanosphere members. We therefore propose that there must exist an active mutualistic relationship established between the diazotrophic copiotrophic heterotrophs and $M$. vaginatus based on a $\mathrm{C}$ for $\mathrm{N}$ exchange. Proof of such a symbiotic relationship will necessitate the deployment of alternative approaches, which could include using ${ }^{13} \mathrm{CO}_{2} /{ }^{15} \mathrm{~N}_{2}$ stable isotope tracers in combination with NanoSIMS imaging for direct visualization of a coupled exchange [44], or, even more directly, the reconstitution of the mutualistic relationship from representative isolates of each partner. Unfortunately, no cultured representatives are yet available of these heterotrophic diazotrophs. Chemical characterization of the $\mathrm{C}$-compound used by the $\mathrm{N}$-fixing heterotrophs and their consumption spectrum by other biocrust organisms [40] would allow to determine how targeted and precisely controlled this $\mathrm{C}$ to $\mathrm{N}$ exchange might be.

In any event, the fact that nitrogen fixation rates do not differ significantly between early-stage and mature biocrusts [15] illustrates the critical role that these heterotrophic diazotrophs may play in the establishment and early development of biocrusts. That $M$. vaginatus carries its own built-in nitrogen fixation "microbiome module" must offer it very significant fitness value as a colonizer of $\mathrm{N}$-depleted soils. In a way, it is $M$. vaginatus plus its cyanosphere that constitutes the true pioneer of biocrust. As such, it should prove interesting to target the use of mixed cultures in current efforts for arid land soil rehabilitation in which inoculation and survival of Microcoleus vaginatus is key [45].

\section{A spatially organized microbiome}

It seems from our results that the powers for spatial organization of the biocrust microbiome by $M$. vaginatus may not be relegated to the formation of a cyanosphere, but potentially extend to a significant proportion of the community that segregates from it. Our effort to interrogate the putative function of those segregating OTUs showed that competitors for light and for $\mathrm{CO}_{2}$ predictably count among them, as did members of typically oligotrophic bacterial groups, as one would have expected. However, given that a large fraction of the segregating OTUs could not be confidently functionally assigned, it is premature to conclude that such distribution patterns based on competition could hold for all. Our knowledge of the principles of microbiome assembly has clearly lagged behind a bewildering advance of the technological ability to describe in detail their complex composition and potential capabilities through "omics" techniques [46]. The use of network theory and analysis has been at the forefront of such efforts $[43,47,48]$. At the base of network studies is the assumption that functional interactions among microbial types are the main drivers of spatial patterns of occurrence, such that detection of microbial co-occurrence can reveal essentially functional networks. This is of course true for cases of obligate, strong interactions like symbioses, which tend to promote the formation of tight, microscale consortial aggregates [49]. Theoretical and experimental work points to subtler nutrient gradients as crucial to the maintenance of spatially structured microbiomes $[50,51]$. If this were correct, one would expect that microbial species that are functionally central in a microbiome will play an inordinately large role on the spatial structuring of the rest of the components (i.e., they will 
effectively landscape the microbiome) through metabolic interactivity. This is precisely what our results seem to imply. Our observations provide a first glimpse at the fact that spatial organization of microbiomes might further constrain and be constrained by metabolic interactivity.

\section{Conclusions}

We physically isolated $M$. vaginatus bundles from the biocrusts they form, taking advantage of their large size, and analyzed the composition of the microbial communities that develop in its close proximity. We found that a diverse set of bacteria inhabit the cyanosphere compartment (202 \pm 97 OTUs) among which a small fraction (21) are significantly more abundant aggregated with $M$. vaginatus, compared to the bulk soil, and that a large number of OTUs significantly tend to segregate from $M$. vaginatus. Phylogenetic placements suggest that all members of the cyanosphere are copiotrophs and many are diazotrophs. By contrary, competition for light, $\mathrm{CO}_{2}$, and low carbon concentrations define at least a part of the OTU that segregate from it. The qPCR assay for nifH strongly suggests that the inhabitants of the cyanosphere also concentrate the nitrogen fixation function in the biocrust. We propose that there exist a mutualism between $M$. vaginatus and copiotrophic diazotrophs in its cyanosphere and that this consortium constitutes the true pioneer community enabling the colonization of nitrogen-poor soils.

\section{Methods}

\section{Sample collection and bundle picking}

We studied biocrusts from two locations in the Southwestern US: the Chihuahuan Desert (near El Paso, TX; 32.431069-105.984151 ${ }^{\circ}$ ) and the Great Basin Desert (near Salt Lake City, UT; 32.54558-106.72324'). The sampling locations have been fully described in Velasco Ayuso et al. [35] and Giraldo Silva et al. [45]. Biocrusts were wetted in situ with distilled water for sampling, then dried, and stored in dark and dry conditions until experimentation, when they were wetted for $24 \mathrm{~h}$ prior to sampling. Using forceps under a dissection scope, we picked $M$. vaginatus bundles from each site (Additional file 2: Table S1, Additional file 5: Video S1), which were then individually washed in autoclaved Milli-Q water, and observed under the microscope to assign species. Five pieces of autoclaved sewing thread, used to mimic $M$. vaginatus bundles, were subjected to the same procedure and used as negative controls. For the respective bulk soil crusts, we sampled in triplicate (6 samples total) taking $0.5 \mathrm{~cm}$ deep and $1 \mathrm{~cm}$ (internal diameter) cores (Additional file 2: Table S1). Each bulk soil, bundle, or control (sewing thread) was transferred to 2-mL tubes containing SDS, and DNA was extracted immediately.
DNA purification, $16 \mathrm{~S}$ library preparation, and sequencing DNA from all samples was isolated using a PowerSoil DNA Isolation Kit (MoBio, Carlsbad CA), following the manufacturer's protocol. General prokaryotic primers targeting the 16S rRNA V4 region: 515F 5'GTGC CAGCMGCCGCGGTAA-3' and, 806R 5'-GGAC TACHVGGGTWTCTAAT-3' [52] were used for library preparation. PCR was performed in triplicate, and products pooled for each sample, with an initial phase of denaturation at $94{ }^{\circ} \mathrm{C}$ for $3 \mathrm{~min}$, followed by 35 cycles (denaturation $64{ }^{\circ} \mathrm{C}$ for $45 \mathrm{~s}$, annealing $50^{\circ} \mathrm{C}$ for $50 \mathrm{~s}$, extension $72^{\circ} \mathrm{C}$ for $90 \mathrm{~s}$ ), followed by a final extension phase at $72^{\circ} \mathrm{C}$ for $10 \mathrm{~min}$. Determination of total DNA concentrations in PCR products was assessed by Quant-iT PicoGreen dsDNA Assay Kit (Life Technologies, New York, USA) and pooled to a total concentration of $240 \mathrm{ng}$ of DNA per sample in the library. DNA was cleaned using the QIA Quick PCR Purification kit (QIAGEN, Valencia, CA, USA). The library DNA concentration was quantified using the Kit ABI Prism ${ }^{\circ}$ (Kapa Biosystems, Wilmington, MA, USA), following the manufacturer's instructions, diluted to a final concentration of $4 \mathrm{nM}$, then denatured and diluted to a final concentration of $4 \mathrm{pM}$, spiked with a $30 \%$ PhiX solution, and then loaded on the MiSeq Illumina Sequencer (Illumina, San Diego, CA, USA). The sequencing was performed in the Microbiome Analysis Laboratory at Arizona State University (Tempe, AZ, USA), using custom primers, paired ends sequencing, and default chemistry.

\section{Quantitative PCR}

Real-time polymerase chain reaction (qPCR) was used to quantify gene copy numbers of $16 \mathrm{~S}$ rRNA and nif $\mathrm{H}$ genes in bulk soil crust and $M$. vaginatus bundles, using appropriate standard primers (respectively: 338F 5'-ACTCCTACGGGAGGCAGCAG-3' 518R 5'-GTAT TACCGCGGCTGCTGG-3' [53] and PolF 5'-TGCG AYCCSAARGCBGACTC-3' PolR 5'-ATSGCCATCATYTCRCCGGA-3') [54]. The expected size of the amplicon was $\sim 180 \mathrm{bp}$ and $\sim 340 \mathrm{bp}$ for the $16 \mathrm{~S}$ rRNA gene and nif $\mathrm{H}$ gene respectively. Two standard curves were made using gBlocks ${ }^{\circ}$ Gene Fragments from Integrated DNA Technologies. The 16S rRNA gene standard curve used a dilution series from $10^{7}$ to 10 gene copy numbers, while for the nifH gene, the dilution series was from $10^{4}$ to 1 copy. For both assays, the reactions were prepared in triplicate in a final volume of $20 \mu \mathrm{l}$. Each reaction contained $5 \mu \mathrm{l}$ of template DNA, $10 \mu \mathrm{l}$ of Sybr Mix Green (TaqMan $), 0.4 \mu \mathrm{l}$ of primers $(500 \mathrm{nM}$ for each), and $4.6 \mu \mathrm{l}$ of water. Two negative controls were used, one with no template and one with no primers. The samples were amplified and quantified using an ABI7900HT thermocycler. The protocol for the 16S rRNA PCR included 
an initial denaturation phase $\left(98^{\circ} \mathrm{C}\right.$ for $\left.2.00 \mathrm{~min}\right)$, followed by 40 cycles of a second phase $\left(95^{\circ} \mathrm{C}\right.$ for $10 \mathrm{~min}$ and finally, $55^{\circ} \mathrm{C}$ for $30 \mathrm{~min}$ ), and then a dissociation stage (beginning at $55^{\circ} \mathrm{C}$ and ending at $95^{\circ} \mathrm{C}$ with a $2 \%$ ramp rate) [18]. For the nif $\mathrm{H}$ gene assay [55], PCR involved an initial denaturation stage $\left(95^{\circ} \mathrm{C}\right.$ for $3 \mathrm{~min}$ ), followed by 45 cycles of $95^{\circ} \mathrm{C}$ for $10 \mathrm{~min}$ and $59^{\circ} \mathrm{C}$ for $30 \mathrm{~min}$, and then a dissociation stage beginning at $59^{\circ} \mathrm{C}$ and ending at $95^{\circ} \mathrm{C}$ with a $2 \%$ ramp rate. The nif $\mathrm{H} / 16 \mathrm{~S}$ rRNA gene ratio was calculated from values of copy number per nanogram of DNA. The final dataset was log transformed to comply with the normality (Shapiro-Wilk test) and variance homogeneity (Levene's test) requirement of a one-way ANOVA test. This test was run to test whether the bundle and soil groups from both FB and HSN locations had different nifH/16S rRNA gene ratios.

\section{Bioinformatics analyses}

The raw FastaQ file was multiplexed within the MiSeq Illumina workflow under default parameters. Retrieved sequences were paired using PANDAseq [56] with an alignment threshold score of 0.95 . High-quality sequences (length $>200 \mathrm{bp}$, minimum average Phred score 25) were further assigned to individual samples, and barcodes were removed using the Qiime 1.8 [57] split_librairies.py script. The master file created was used to pick operational taxonomic units (OTUs) using the pick_open_reference_otus.py pipeline in Qiime under default parameters. More specifically, we used the UCLUST algorithm [58] to pick OTUs at a $97 \%$ similarity threshold and assigned taxonomy using the rdp [59] classifier against the Greengenes reference database release 13.5 [60] (Additional file 1: Table S5). The OTU table produced was filtered to remove rare OTUs including potential chimeras, and only OTUs shared by at least 3 samples in the dataset were kept. Overall, these steps filtered out $5 \%$ of the total sequence count and $70 \%$ of the OTU count. All sequences attributable to Microcoleus vaginatus (see the "Phylogenetic analyses" section for taxonomic assignments) were removed from the OTU table. The $M$. vaginatus-free table was Hellinger normalized using the decostand script of the $R$ vegan package. Beta diversity Bray-Curtis pairwise distances were calculated on the Hellinger-transformed matrix and further ordinated using NMDS in Qiime (NMDS coordinates can be found in Additional file 6: Table S6). The significance of differential OTU distribution between bundles vs. bulk soil crust was assessed using an Adonis test on the Bray-Curtis distance matrix with the compare_categories.py Qiime script. We further determined which OTUs were differentially abundant in the bundles vs. total community using the DeSeq2 method [36]. After checking the good agreement between the fit line and the shrinked data on the dispersion plot, a Wald test was applied to each OTU to reject the null hypothesis ( $p$ value $<0.05$ ) that the logarithmic fold change between communities (i.e., in our case bundle vs. bulk soil crust) for a given OTU is null. The 5 control samples (sewing thread) were analyzed the same way in an effort to account for any external contamination (i.e., operator or environmental source) in our bundle sample handling.

\section{Phylogenetic analyses}

Phylogenetic placement of the 21 aggregating and 1160 segregating OTU sequences was resolved by constructing 16 trees encompassing their phylogenetic diversity. For all but the cyanobacteria tree, the dataset used was a combination of our sequences along with their first Blastn hit and the closest cultured relative downloaded from SILVA rRNA database project and the NCBI $16 \mathrm{~S}$ ribosomal RNA sequences (see supplementary OTU_classifier.ipynb). Each phylum-level dataset was then treated independently. Sequences were aligned with SSU-ALIGN [61], using a profile-based alignment strategy, in which each target sequence is aligned independently to a covariance model that uses the $16 \mathrm{~S}$ rRNA gene secondary structure. Poorly aligned columns were removed from the alignment based on a $95 \%$ confidence profile calculated within SSU-ALIGN. The alignment was trimmed to coordinates on Geneious version 8.0 [62], so all sequences in the alignment will begin and end at the same positions. Tree topology was inferred on the CIPRES high-performance computing cluster [63], using the RAxML-HPC2 [64] workflow on XSEDE with the ML + Thorough bootstrap (1000 bootstraps) method and the GTRGAMMA model. For the cyanobacteria tree, all $16 \mathrm{~S}$ rRNA gene sequences of at least $1100 \mathrm{bp}$ were manually downloaded from NCBI [65]. A reference alignment was built from these 1034 high-quality sequences using SSU-ALIGN [66]. The reference cyanobacteria tree (https:/github.com/FGPLab/cydrasil/tree/0.22a) was constructed on the CIPRES high-performance computing cluster [63], using the RAxML-HPC2 [64] workflow on XSEDE with the ML + Thorough bootstrap (1000 bootstraps, GTRGAMMA model). Cyanobacteria OTU sequences were aligned to the reference alignment with PaPaRa [67] using a probabilistic gap model and then placed into the reference tree using the RaxML8 Evolutionary Placement Algorithm [68]. Additionally, the RaxML8 Evolutionary Placement Algorithm [68] was used for some of the previously constructed trees (Acidobacteria, Deinococcus-Thermus, Armatimonadetes, Chlorobi, Chloroflexi, Firmicutes, Planctomycetes, and Verrucomicrobia) in an effort to taxonomically assign as many OTUs as possible. The resulting trees were imported into the iTOL 3 server [69] and can be visualized at http://itol.embl.de/shared/ 
microbiomelandscaper; aggregating sequences are shown in red while segregating sequences are in blue.

\section{Additional files}

Additional file 1: Table S2. Taxonomic assignments and functional inference based on phylogenetic placement for aggregating (cyanosphere) OTUs in the cold desert (HSN). Table S3. Taxonomic assignments and functional inference based on phylogenetic placement for aggregating (cyanosphere) OTUs in the hot desert (FB). (DOCX $38 \mathrm{~kb}$ )

Additional file 2: Table S1. Summary of SSU rRNA gene libraries analyzed from HSN and FB sample set and associated coverage and a-diversity indices. (DOCX $23 \mathrm{~kb}$ )

Additional file 3: Table S4. Taxonomic assignment and functional inferences based on phylogenetic placement for segregating OTUs for both bulk soils (cold and hot deserts). Rows colored in yellow correspond to OTUs for which inferred function was consistent with segregation from M. vaginatus. (DOCX $192 \mathrm{~kb}$ )

Additional file 4: Table S5. Potential contaminants. Responding OTUs detected after amplification and sequencing of negative controls $(n=5)$ without target Microcoleus bundles. (DOCX $17 \mathrm{~kb}$ )

Additional file 5: Video S1. Manipulative isolation of M. vaginatus bundles under the dissection microscope. (MP4 $17474 \mathrm{~kb}$ )

Additional file 6: Table S6. NMDS plot coordinates. The corresponding plot is displayed in Fig. 3a (DOCX $18 \mathrm{~kb})$

\section{Acknowledgements}

We thank Susanne Neuer, Albert Ruhí, Daniel Roush and Tara Rodkey for their help. We thank Simon Delattre for his help writing the OTU_classifier.ipynb script.

\section{Funding}

This work was supported by a Strategic Environmental Research and Development Grant (SERDP) (W912HQ-13-C-0035-P00005 RC-2329) of the US Department of Defense. This project has received funding from the European Union's Seventh Framework Programme for research; technological development and demonstration under grant agreement no 328530.

\section{Availability of data and materials}

The datasets generated and/or analyzed during the current study are available in the NCBI Bioproject repository under accession number PRJNA397464.

\section{Authors' contributions}

EC, AGS, and FGP carried out the experimental design. EC and AGS performed the laboratory research and further data process and analyses. FDM carried out the GPCR protocol design and laboratory execution. EC, AGS, and FGP wrote the manuscript. All authors contributed to the discussion of data and finalization of the manuscript. All authors read and approved the final manuscript.

\section{Ethics approval and consent to participate}

Not applicable.

\section{Consent for publication}

Not applicable.

\section{Competing interests}

The authors declare that they have no competing interests.

\section{Publisher's Note}

Springer Nature remains neutral with regard to jurisdictional claims in published maps and institutional affiliations.

\section{Author details}

${ }^{1}$ School of Life Sciences, Arizona State University, 427 E. Tyler Mall, Tempe, AZ 85287, USA. ²aboratoire Biogéosciences, Université de Bourgogne, Dijon,
France. ${ }^{3}$ Present Address: Joint Genome Institute (DOE), Lawrence Berkeley National Lab (LBNL), 2800 Mitchell Drive, Walnut Creek, CA 94598, USA. ${ }^{4}$ Center for Fundamental and Applied Microbiomics, Biodesign Institute, Arizona State University, 1001 S. McAllister Ave., Tempe, AZ 85282, USA.

Received: 21 September 2018 Accepted: 11 March 2019

Published online: 03 April 2019

\section{References}

1. Garcia-Pichel F. Desert environments: biological soil crusts. Environemental Microbiol: Encycl; 2003.

2. Belnap J, Budel B, Lange OL. Biological soil crusts: characteristics and distribution. In: Biol soil crusts struct funct manag. Berlin: Springer; 2001. p. 3-30.

3. Webber B, Budel B, Belnap J. Biological soil crusts: an organizing principle in drylands. Ecological. Switzerland: Springer; 2016.

4. Abed RMM, Ramette A, Hübner V, De Deckker P, de Beer D. Microbial diversity of eolian dust sources from saline lake sediments and biological soil crusts in arid Southern Australia. FEMS Microbiol Ecol. 2012;80:294-304 Available from: http://www.ncbi.nlm.nih.gov/pubmed/22224563. [cited 20 Dec 2013].

5. Kuske CR, Yeager CM, Johnson S, Ticknor LO, Belnap J. Response and resilience of soil biocrust bacterial communities to chronic physical disturbance in arid shrublands. ISME J. 2012;6:886-97 Available from: http:// www.ncbi.nlm.nih.gov/pubmed/22113374. [cited 2012 Dec 20]. Nature Publishing Group.

6. Garcia-Pichel F, Wojciechowski MF. The evolution of a capacity to build supra-cellular ropes enabled filamentous cyanobacteria to colonize highly erodible substrates Rodriguez-Valera F, editor PLoS One. 2009;4:e7801. Available from: http://www.pubmedcentral.nih.gov/articlerender.fcgi?artid= 2773439\&tool=pmcentrez\&rendertype=abstract. [cited 2012 Oct 16]. Public Library of Science

7. Yeager CM, Kornosky JL, Morgan RE, Cain EC, Garcia-Pichel F, Housman DC, et al. Three distinct clades of cultured heterocystous cyanobacteria constitute the dominant N2-fixing members of biological soil crusts of the Colorado Plateau, USA. FEMS Microbiol Ecol. 2007;60:85-97 Available from: http://www.ncbi.nlm.nih.gov/pubmed/17381526. [cited 2013 Jun 26].

8. Gundlapally SR, Garcia-Pichel F. The community and phylogenetic diversity of biological soil crusts in the Colorado Plateau studied by molecular fingerprinting and intensive cultivation. Microb Ecol. 2006;52:345-57 Available from: http://www.ncbi.nlm.nih.gov/pubmed/16691327. [cited 5 Jun 2013].

9. Soule T, Anderson IJ, Johnson SL, Bates ST, Garcia-Pichel F. Archaeal populations in biological soil crusts from arid lands in North America. Soil biol Biochem. 2009;41:2069-74. https://doi.org/10.1016/j.soilbio.2009.07.023 Elsevier Ltd.

10. Bates ST, Nash TH, Garcia-Pichel F. Patterns of diversity for fungal assemblages of biological soil crusts from the southwestern United States. Mycologia. 2012;104:353-61 Available from: https:/www.tandfonline.com/ doi/full/10.3852/11-232.

11. Bates ST, Nash TH, Sweat KG, Garcia-Pichel F. Fungal communities of lichendominated biological soil crusts: diversity, relative microbial biomass, and their relationship to disturbance and crust cover. J Arid Environ. 2010;74: 1192-9. https://doi.org/10.1016/j.jaridenv.2010.05.033 Elsevier Ltd.

12. Antoninka A, Bowker MA, Reed SC, Doherty K. Production of greenhousegrown biocrust mosses and associated cyanobacteria to rehabilitate dryland soil function. Restor Ecol. 2016;24:324-35.

13. Nunes da Rocha U, Cadillo-Quiroz H, Karaoz U, Rajeev L, Klitgord N, Dunn S, et al. Isolation of a significant fraction of non-phototroph diversity from a desert biological soil crust. Front Microbiol. 2015;6:1-14 Available from: http://journal.frontiersin.org/article/10.3389/fmicb.2015.00277/abstract.

14. Marusenko Y, Bates ST, Anderson I, Johnson SL, Soule T, Garcia-Pichel F. Ammonia-oxidizing archaea and bacteria are structured by geography in biological soil crusts across North American arid lands. Ecol Process. 2013;2:1-10.

15. Johnson SL, Budinoff CR, Belnap J, Garcia-Pichel F. Relevance of ammonium oxidation within biological soil crust communities. Environ Microbiol. 2005;7:1-12.

16. Karaoz U, Couradeau E, da Rocha UN, Lim H-C, Northen T, Garcia-Pichel F, et al. Large blooms of Bacillales (Firmicutes) underlie the response to wetting of cyanobacterial biocrusts at various stages of maturity. MBio. 2018;9:1-17.

17. Angel R, Matthies D, Conrad R. Activation of methanogenesis in arid biological soil crusts despite the presence of oxygen. PLoS One. 2011;6:1-8.

18. Couradeau E, Karaoz U, Lim HC, Nunes da Rocha U, Northen T, Brodie E, et al. Bacteria increase arid-land soil surface temperature through the production of sunscreens. Nat Commun. 2016;7:10373 Available from: 
http://www.nature.com/doifinder/10.1038/ncomms10373. Nature Publishing Group.

19. Nagy ML, Pérez A, Garcia-Pichel F. The prokaryotic diversity of biological soil crusts in the Sonoran Desert (Organ Pipe Cactus National Monument, AZ). FEMS Microbiol Ecol. 2005;54:233-45 Available from: http://www.ncbi.nlm. nih.gov/pubmed/16332322. [cited 23 may 2013].

20. Garcia-Pichel F, Loza V, Marusenko Y, Mateo P, Potrafka RM. Temperature drives the continental-scale distribution of key microbes in topsoil communities. Science. 2013;340:1574-7 Available from: http://www. sciencemag.org/cgi/doi/10.1126/science.1236404. American Association for the Advancement of Science; [cited 15 Aug 2013].

21. Rajeev L, da Rocha UN, Klitgord N, Luning EG, Fortney J, Axen SD, et al. Dynamic cyanobacterial response to hydration and dehydration in a desert biological soil crust. ISME J. 2013:1-14 Available from: http:// www.nature.com/doifinder/10.1038/ismej.2013.83. Nature Publishing Group; [cited Jun 6 2013].

22. Garcia-Pichel F, Belnap J. Small-scale environments and distribution of biological soil crusts. Biol soil crusts Struct Funct Manag. Berlin: Springer; 2001. p. 193-201.

23. Rodríguez-Caballero E, Belnap J, Büdel B, Crutzen P, Andreae MO, Pöschl U, et al. Dryland photoautotrophic soil surface communities endangered by global change. Nat Geosci. 2017;11:181-9.

24. Elbert W, Weber B, Burrows S, Steinkamp J, Büdel B, Andreae MO, et al. Contribution of cryptogamic covers to the global cycles of carbon and nitrogen. Nat Geosci. 2012;5:459-62 Available from: http://www.nature.com/ doifinder/10.1038/ngeo1486. Nature Publishing Group; [cited 2013 Mar 1].

25. Barger NN, Weber B, Garcia-Pichel F, Zaady E, Belnap J. Patterns and controls on nitrogen cycling of biological soil crusts. Biol soil crusts an Organ Princ drylands. Switzerland: Springer; 2016. p. 257-85.

26. Garcia-Pichel F, Belnap J, Neuer S, Schanz F. Estimates of global cyanobacterial biomass and its distribution. Arch Hydrobiol Suppl Algol Stud. 2006;109:213-27.

27. Beraldi-Campesi H, Farmer JD, Garcia-Pichel F. Modern terrestrial sedimentary biostructures and their fossil analogs in Mesoproterozoic subaerial deposits. Palaios. 2014;29:45-54 Available from: http://palaios, sepmonline.org/content/29/2/45.abstract.

28. Thomazo C, Couradeau E, Garcia-Pichel F. Possible nitrogen fertilization of the early Earth Ocean by microbial continental ecosystems. Nat Commun. 2018;9:1-8.

29. Baran R, Brodie EL, Mayberry-Lewis J, Hummel E, Da Rocha UN, Chakraborty $R$, et al. Exometabolite niche partitioning among sympatric soil bacteria. Nat Commun. 2015;6:8289 Available from: http://www.nature.com/doifinder/10. 1038/ncomms9289. Nature Publishing Group.

30. Baran R, Ivanova NN, Jose N, Garcia-Pichel F, Kyrpides NC, Gugger M, et al. Functional genomics of novel secondary metabolites from diverse cyanobacteria using untargeted metabolomics. Mar Drugs. 2013;11:3617-31 Available from: http://www.pubmedcentral.nih.gov/ articlerender.fcgi?artid=3826126\&tool=pmcentrez\&rendertype=abstract. [cited 23 Jan 2014].

31. Starkenburg SR, Reitenga KG, Freitas T, Johnson S, Chain PSG, Garcia-Pichel $\mathrm{F}$, et al. Genome of the cyanobacterium Microcoleus vaginatus FGP-2, a photosynthetic ecosystem engineer of arid land soil biocrusts worldwide. J Bacteriol. 2011;193:4569-70 Available from: http://www.pubmedcentral.nih. gov/articlerender.fcgi?artid=3165530\&tool=pmcentrez\&rendertype=abstract. [cited 2012 Oct 8]

32. Jose NA, Lau R, Swenson TL, Klitgord N, Garcia-Pichel F, Bowen BP, et al. Flux balance modeling to predict bacterial survival during pulsed-activity events. Biogeosciences. 2018;15:2219-29.

33. Pepe-Ranney C, Koechli C, Potrafka R, Andam C, Eggleston E, GarciaPichel $F$, et al. Non-cyanobacterial diazotrophs dominate dinitrogen fixation in biological soil crusts during early crust formation. Isme J. 2016:10:287-98.

34. Sasse J, Martinoia E, Northen T. Feed your friends: do plant exudates shape the root microbiome? Trends plant Sci. 2018;23:25-41 Elsevier Ltd. Available from: https://doi.org/10.1016/j.tplants.2017.09.003.

35. Ayuso Velasco S, Giraldo Silva A, Nelson C, Barger NN, Garcia-Pichel F. Microbial nursery production of high-quality biological soil crust biomass for restoration of degraded dryland soils. Appl Environ Microbiol. 2017;83:1-16.

36. McMurdie PJ, Holmes S. Waste not, want not: why rarefying microbiome data is inadmissible. McHardy AC, editor PLoS Comput Biol. 2014;10: e1003531. Available from: http://dx.plos.org/10.1371/journal.pcbi.1003531
37. Kuzyakov Y, Blagodatskaya E. Microbial hotspots and hot moments in soil: concept \& review. Soil biol Biochem. 2015;83:184-99. https://doi.org/10. 1016/j.soilbio.2015.01.025 Elsevier Ltd.

38. Graham LE, Graham JM, Wilcox LW, Cook ME, Arancibia-Avila P, Knack JJ. Evolutionary roots of plant microbiomes and biogeochemical impacts of nonvascular autotroph-microbiome systems over deep time. Int J Plant Sci. 2018;179:000 Available from: https://www.journals.uchicago.edu/doi/10. 1086/698709.

39. Lynch MDJ, Neufeld JD. Ecology and exploration of the rare biosphere. Nat rev Microbiol. 2015;13:217-29 Available from: http:/www.nature.com/ doifinder/10.1038/nrmicro3400. Nature Publishing Group.

40. Swenson TL, Karaoz U, Swenson JM, Bowen BP, Northen TR. Linking soil biology and chemistry in biological soil crust using isolate exometabolomics. Nat Commun. Springer US. 2018:9. https://doi.org/10. 1038/s41467-017-02356-9.

41. Swenson TL, Couradeau E, Bowen BP, de Philippis R, Rossi F, Mugnai G, et al. A novel method to evaluate nutrient retention by biological soil crust exopolymeric matrix. Plant Soil. 2017:429:53-64.

42. Couradeau E, VJ MNLF, Parkinson D, Uteau D, Rochet A, Cuellar C, et al. In situ $x$-ray tomography imaging of soil water and cyanobacteria from biological soil crusts undergoing desiccation. Front Environ Sci. 2018;1:65 Available from: https:/www.frontiersin.org/articles/10.3389/fenvs.2018.00065/full.

43. Coyte KZ, Schluter J, Foster KR. The ecology of the microbiome: networks, competition, and stability. Science (80- ). 2015;350:663-6 Available from: http://www.sciencemag.org/content/350/6261/663.abstract.

44. Samo TJ, Kimbrel JA, Nilson DJ, Pett-Ridge J, Weber PK, Mayali X. Attachment between heterotrophic bacteria and microalgae influences symbiotic microscale interactions. Environ Microbiol. 2018; Available from: http://doi.wiley.com/10.1111/1462-2920.14357.

45. Giraldo Silva A, Nelson C, Barger NN, Garcia-Pichel F. Nursing biocrusts: isolation, cultivation, and fitness test of indigenous cyanobacteria. Restor Ecol. 2018:1-11.

46. Parks DH, Rinke C, Chuvochina M, Chaumeil P-A, Woodcroft BJ, Evans PN, et al. Recovery of nearly 8,000 metagenome-assembled genomes substantially expands the tree of life. Nat Microbiol. 2017;903:1-10 Available from: http:// www.nature.com/articles/s41564-017-0012-7. Springer US.

47. Guidi L, Chaffron S, Bittner L, Eveillard D, Larhlimi A, Roux S, et al. Plankton networks driving carbon export in the oligotrophic ocean. Nature. 2015;532: in review. Nature Publishing Group; Available from: https:/doi.org/10.1038/ nature 16942

48. Milo R, Shen-Orr S, Itzkovitz S, Kashtan N. Network motif: simple building blocks of complex networks. Science (80- ). 2002;298:298.

49. Hatzenpichler R, Connon SA, Goudeau D, Malmstrom RR, Woyke T, Orphan VJ. Visualizing in situ translational activity for identifying and sorting slowgrowing archaeal-bacterial consortia. Proc Natl Acad Sci. 2016;113:E4069-78 Available from: http://www.pnas.org/lookup/doi/10.1073/pnas.1603757113.

50. Nadell CD, Foster KR, Xavier JB. Emergence of spatial structure in cell groups and the evolution of cooperation. PLoS Comput Biol. 2010;6:1-9.

51. Mitri S, Clarke E, Foster KR. Resource limitation drives spatial organization in microbial groups. ISME J. Nature Publishing Group; 2015;10:1-12. Available from: https://doi.org/10.1038/ismej.2015.208

52. Caporaso JG, Lauber CL, Walters WA, Berg-Lyons D, Lozupone CA, Turnbaugh PJ, et al. Global patterns of $16 \mathrm{~S}$ rRNA diversity at a depth of millions of sequences per sample. Proc Natl Acad Sci U S A. 2011;108 Suppl: 4516-22 Available from: https://www.pnas.org/content/108/Supplement_1/ 4516. Department of Chemistry and Biochemistry, University of Colorado, Boulder, CO 80309, USA.

53. Nübel U, Garcia-Pichel F, Muyzer G. PCR primers to amplify 165 rRNA genes from cyanobacteria PCR primers to amplify 165 rRNA genes from cyanobacteria. Appl Environ Microbiol. 1997;63:3327-32.

54. Poly F, Monrozier LJ, Bally R. Improvement in the RFLP procedure for studying the diversity of nifH genes in communities of nitrogen fixers in soil. Res Microbiol. 2001;152:95-103.

55. Ceja-Navarro JA, Nguyen NH, Karaoz U, Gross SR, Herman DJ, Andersen $\mathrm{GL}$, et al. Compartmentalized microbial composition, oxygen gradients and nitrogen fixation in the gut of Odontotaenius disjunctus. ISME J. 2014;8:6-18.

56. Masella AP, Bartram AK, Truszkowski JM, Brown DG, Neufeld JD. PANDAseq: paired-end assembler for illumina sequences. BMC Bioinf. 2012;13:31 Available from: http://www.biomedcentral.com/1471-2105/13/31. BioMed Central Ltd. [cited 23 May 2014]. 
57. Caporaso JG, Kuczynski J, Stombaugh J, Bittinger K, Bushman FD, Costello EK, Fierer N, Peña AG, Goodrich JK, Gordon Jl, Huttley GA, Kelley ST, Knights D, Koenig JE, Ley RE, Lozupone CA, Mcdonald D, Muegge BD, Pirrung M, Reeder J, Sevinsky JR, Turnbaugh PJKR. QIIME allows analysis of highthroughput community sequencing data. Nat Methods. 2010;7:335-6.

58. Edgar RC. Search and clustering orders of magnitude faster than BLAST. Bioinformatics. 2010;26:2460-1.

59. Wang Q, Garrity GM, Tiedje JM, Cole JR. Naive Bayesian classifier for rapid assignment of rRNA sequences into the new bacterial taxonomy. Appl Environ Microbiol. 2007;73:5261-7 Available from: http://www. pubmedcentral.nih.gov/articlerender.fcgi?artid=1950982\&tool= pmcentrez\&rendertype=abstract. [cited 9 Jul 2014].

60. McDonald D, Price MN, Goodrich J, Nawrocki EP, DeSantis TZ, Probst A, et al. An improved Greengenes taxonomy with explicit ranks for ecological and evolutionary analyses of bacteria and archaea. ISME J. 2012;6:610-8 Available from: http://www.pubmedcentral.nih.gov/articlerender.fcgi?artid= 3280142\&tool=pmcentrez\&rendertype=abstract. Nature Publishing Group. [cited 9 Jul 2014].

61. Nawrocki EP. Structural RNA homology search and alignment using covariance models. in St. Louis: Washington University; 2009.

62. Kearse M, Moir R, Wilson A, Stones-Havas S, Cheung M, Sturrock S, et al. Geneious basic: an integrated and extendable desktop software platform for the organization and analysis of sequence data, vol. 28; 2012. p. 1647-9. Available from: http://bioinformatics.oxfordjournals.org/cgi/doi/10.1093/ bioinformatics/bts199

63. Miller MA, Pfeiffer W, Schwartz T. Creating the CIPRES Science Gateway for inference of large phylogenetic trees. 2010 Gatew Comput Environ Work GCE 2010; 2010.

64. Stamatakis A. RAxML version 8: a tool for phylogenetic analysis and postanalysis of large phylogenies. Bioinformatics. 2014;30:1312-3.

65. Bethesda (MD): National Library of Medicine (US) NC for BI. National Center for Biotechnology Information (NCBI). 1988. p. https://www.ncbi.nlm.nih.gov/.

66. Bethesda (MD): National Library of Medicine (US) NC for BI. 16s ribosomal RNA sequences (bacteria/archaea). 2004. p. https://www.ncbi.nlm.nih.gov/ refseq/targetedloci/.

67. Berger SA, Stamatakis A. Aligning short reads to reference alignments and trees. Bioinformatics. 2011;27:2068-75.

68. Berger SA, Krompass D, Stamatakis A. Performance, accuracy, and web server for evolutionary placement of short sequence reads under maximum likelihood. Syst Biol. 2011;60:291-302 The Exelixis Lab, Scientific Computing Group, Heidelberg Institute for Theoretical Studies, SchlossWolfsbrunnenweg 35, D-69118 Heidelberg, Germany: Oxford University Press; Available from: http://sysbio.oxfordjournals.org/content/60/3/291.full.

69. Letunic I, Bork P. Interactive Tree Of Life (iTOL): an online tool for phylogenetic tree display and annotation. Bioinformatics. 2007;23:127-8.

Ready to submit your research? Choose BMC and benefit from:

- fast, convenient online submission

- thorough peer review by experienced researchers in your field

- rapid publication on acceptance

- support for research data, including large and complex data types

- gold Open Access which fosters wider collaboration and increased citations

- maximum visibility for your research: over $100 \mathrm{M}$ website views per year

At BMC, research is always in progress.

Learn more biomedcentral.com/submissions 